\title{
A New Method for Descaling Wool Fibres by Nano Abrasive Calcium Carbonate Particles in Ultrasonic Bath
}

\author{
ALIREZA GHASEMI', SAFDAR ESKANDARNEJAD ${ }^{1}$, \\ RAMIN KHAJAVI ${ }^{2}$ and MOHAMMAD BAMENI MOGHADAM ${ }^{3}$ \\ ${ }^{1}$ Textile Department, Science and Research Branch Islamic Azad University, Tehran, Iran. \\ 2Polymer and Textile Dept., South Tehran Branch, Islamic Azad University, Tehran, Iran. \\ ${ }^{3}$ Department of Statistics, Allameh Tabataba'I University, Tehran, Iran. \\ ${ }^{*}$ Corresponding author E-mail: eskandarnejad@ srbiau.ac.ir
}

http://dx.doi.org/10.13005/ojc/320456

(Received: May 24, 2016; Accepted: July 20, 2016)

\begin{abstract}
Up to now, the most conventional methods for descaling of wool fibre are based on chemical degradation and resin covering of scales or a combination of them. These methods are producing wastewater and can cover physical properties of the fibres beside scales orderly. In this study, a new and clean method is developed on the basis of abrasion effect of calcium carbonate Nano particles (CCNP) in an ultrasonic bath. Woolen Samples (fibre and yarn) were sonicated with different levels of CCNP. Tensile properties of the yarns, directional friction effect of the fibres and scanning electron microscope images of the fibres were studied. Test results showed that sonicated Nano treatment of wool yarn reduced its tenacity, extension and work of rupture and increased its coefficient of friction. Scanning electron microscope images of fibres and measurement of fibres directional displacement confirmed descaling of Nano abrasive treated wool samples in comparison to the raw wool.
\end{abstract}

Keywords: Wool, Descaling, Nano abrasive $\mathrm{CaCO}_{3}$, Ultrasonic, tenacity, directional friction, SEM.

\section{INTRODUCTION}

Wool fibers form $3 \%$ of total world fibers consumed in the production of textiles ${ }^{1}$. Wool fabric shows a high amount of wrinkle resistance and stability of Shape which is due to the excellent recovery from deformations of the fibre. It possesses an outstanding thermal insulating power. This is partly due to the natural curliness of the fibre which causes a rather bulky cloth with much air in it. Wool is subject to biological attack; the fibre is readily eaten by moth larvae and some other insects, a fact which causes large economic losses. A second defect of wool is its shrinkage, this being an unwanted decrease of the dimensions of a fabric during its $u^{2} e^{2}$. When a wool fabric is worked in presence of a solution of soap or acid, shrinkage takes place because the fibres migrate in the direction of their 
root ends, owing to the ratchet-like arrangement of the surface scales. During this migration a fibre which lies originally stretched in the yarn of which the fabric is composed, undergoes displacements and attains a looped and curled position².

The special feature of animal hair fibres by which they show felting power, is their scale structure which gives rise to a difference in friction in two directions along the fibre. Thus irreversible displacement occur, whereas for fibres without scales the total displacement under the influence of forces directed at random is Zero ${ }^{2}$. The friction of wool fibre depends on the direction in which it is pulled: the resistance is greater when it is pulled against the scales than when it is pulled with them. This is known as the directional frictional effect (D.F.E.) ${ }^{3}$. When a material containing wool fibres is submitted to mechanical action such as occurs in laundering or in fulling processes the fibres tend to migrate in the direction of their roots. This migration tendency is recognized as one of the principal factors in the formation of the entangled mass known as a felt, and in the excessive shrinkage which wool materials exhibit during laundering 4 .

Martin showed that, D.F.E. still existed when a wool fibre was rubbed against a polished glass surface though no interlocking or ploughing action of the scales was to be expected in this case ${ }^{5}$. Rudall

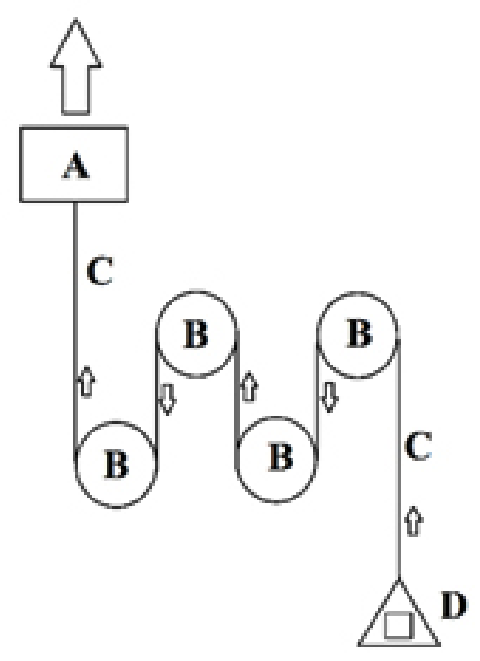

Fig. 1: Schematic diagram of yarn path for determination of yarn coefficient of friction proposed a model with flexible scale tips; this model is also able to explain the decrease of D.F.E. after various chemical anti-shrink processes, in terms of softening or even a removal of the scale tips ${ }^{6}$. The first investigator who took notice of the influence of the scaliness on felting was Bowman. He introduced the interlocking scale theory in which the fibres are supposed to lock into each other by means of their scales and to form in this way an irreversible structure $^{7}$. This theory met the criticism that the scale geometry is not regular enough to enable such interlocking over a number of consecutive scales and that microscopically this phenomenon is never observed. The theory was, therefore, modified in this respect that only few points of interlocking will occur on each fibre. Ditzel was the first who drew the attention to the role played by the root ends of the fibre $^{8}$. These ideas were taken up in 1944 by Martin who prepared some locks of wool by removing the scales from either the root ends or the tip ends ${ }^{9}$.

Various attempts have been made to remove cuticle from wool by simple mechanical methods ${ }^{10,11,12}$, by ultra-sonication ${ }^{13}$ or simply shaking in formic acid ${ }^{14,15}$, or by more degradative chemical procedures ${ }^{13}$. Treatment in formic acid at room temperature causes very uneven removal of the cuticle ${ }^{13}$. A treatment in boiling formic acid with agitation removes virtually all the cuticle from the fibres ${ }^{13}$. The optimum treatment for the removal of virtually all cuticle with minimal removal of cortical cells is a 20-min reflux in formic acid, followed by 16 hr. shaking in formic acid at room temperature ${ }^{16}$.

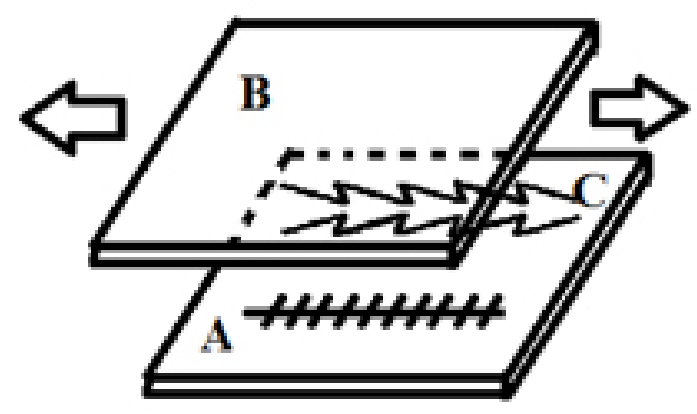

A- Flat glass covered by mm-scaled paper

B- Flat glass covered by sponge and a sheet of paper

C- Wool fibre located between two glass plates

Fig. 2: Glass plates for measurement of directional displacement ${ }^{26}$ 
Commercial methods of obtaining an unshrinkable finish on wool textile materials are based on chemical modification of the surface scale structure, although several methods are available for descaling fibres in the laboratory ${ }^{17}$. King, for example, showed that single wool fibres can be descaled by drawing them under tension over the edge of a microscope slide ${ }^{18}$, and human hair fibres was descaled by drawing between folded strips of emery paper under slight pressure ${ }^{17}$. The use of enzymes to achieve wool shrink resistance, better whiteness and improved handle are also successfully employed in wool bleaching ${ }^{19}$. In two hours the scale layers of the papain treated fibres were completely destroyed and resulted in a smooth surface without any scales. For longer periods (more than two hours) the effects of the trypsin attacks on the scales are presented elsewhere ${ }^{20}$.

Chlorination process causes damages to cuticle layer of wool and hence deterioration of strength and work of rupture in general ${ }^{21}$. Wool scoured in ultrasonic bath has less fibre felting. Coefficient of friction of fabrics treated in ultrasound bath increased due to a change in texture of surface fibres $^{21}$. An increase in intensity of ultrasonic waves during washing process could reduce fabric strength, although $\mathrm{Li}$ et al. showed that washing in ultrasonic bath didn't change fabric strength significantly ${ }^{22,23}$. Surface of wool fibre is greasy and polluted, and must be washed at a stage. It is reported that, chemistry of the effluent generated by scouring of fine quality Merino wool was different from that of Indian carpet grade wool ${ }^{24}$. Corona discharge is being used widely to modify surface texture of textiles and polymers. It is reported that, an increase in power and number of corona treatments increased cracks and hoes on the surface of the treated leather ${ }^{25}$. Wool fabrics can be made unshrinkable by impregnating them with oil and a finely divided abrasive, followed by mechanical working in a milling machine. Under these conditions the scale edges of the fibres are removed and effectiveness of the abrasive increases with increasing fineness and hardness. Among a large number of powders examined, 200-mesh (I.M.M.) silica gave the highest degree of unshrinking ability ${ }^{17}$.

The purpose of this research for descaling of wool is to avoid chemical methods and use mechanical ones together with application of a Nano abrasive material with suitable hardness. If
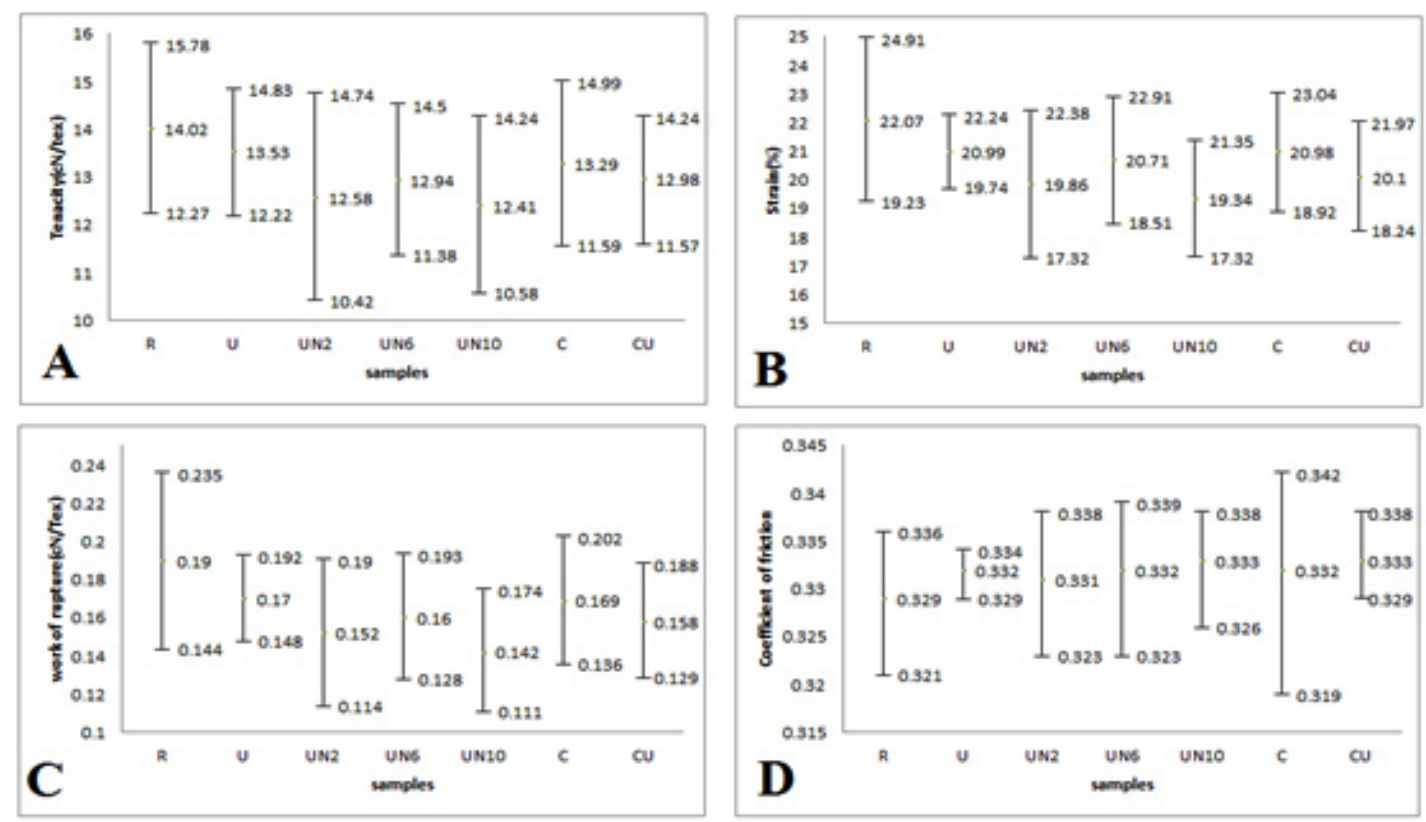

A- Yarn tenacity (cN/tex); B- strain at beak (\%); C- Work of rupture; D- Coefficient of friction

Fig. 3: Results of yarn properties 
this process is successful, it could be an eco-friendly method of wool descaling and prevent environmental pollution.

\section{EXPERIMENTAL}

\section{Materials}

Raw material used was 23 Tex wool/ polyester (45-55) single yarn and raw wool fibre with mean diameter of 35 Micron. The abrasive material used was calcium carbonate Nano particle $(60 \mathrm{~nm})$ and chemicals of sodium hypochlorite $(\mathrm{NaOCl})$ and hydrochloric acid $(\mathrm{HCl})$.

\section{Methods}

Yarn samples were immersed loosely in an ultrasonic bath of $35 \mathrm{KHz}, 40$ watt, containing

Table 1: Fibre and yarn codes

\section{Sample Code Treatment}

\begin{tabular}{|c|c|c|}
\hline 1 & $\mathrm{R}$ & Raw wool \\
\hline 2 & $U$ & Sonicated raw wool \\
\hline 3 & UN2 & $\begin{array}{l}\text { Sonicated in } 2 \text { g/lit Nano } \\
\text { material }\end{array}$ \\
\hline 4 & UN6 & $\begin{array}{l}\text { Sonicated in } 6 \mathrm{~g} / \text { lit Nano } \\
\text { material }\end{array}$ \\
\hline 5 & UN10 & $\begin{array}{l}\text { Sonicated in } 10 \mathrm{~g} / \text { lit Nano } \\
\text { material }\end{array}$ \\
\hline 6 & $\mathrm{C}$ & Chlorinated \\
\hline 7 & $\mathrm{CU}$ & Chlorinated in ultrasonic bath \\
\hline
\end{tabular}

calcium carbonate Nano particles (CCNP) in different concentrations of 2, 6 and $10 \mathrm{~g} / \mathrm{lit}$. The yarns were descaled at 37 pC temperature for $35 \mathrm{~min}$. In order to prevent twist loss of the yarns, both ends of the yarn samples were tied together. Usually results of a new experiment must be compared with an ordinary one. In this study, results were compared with chlorination method of descaling as an ordinary one. One of the samples were chlorinated in ultrasonic bath in order to recognize effect of sonication on chlorination method of descaling. The yarns were coded as $\mathrm{R}$ for raw wool, $\mathrm{U}$ for ultrasound treated, $\mathrm{C}$ for chlorinated, $\mathrm{N}$ for Nano treated together with 2, 6 and 10 for concentrations of 2, 6 and $10 \mathrm{~g} /$ lit. Table 1 shows yarn treatment codes for fibre and yarn.

Mechanical properties such as strength, elongation and work of rupture of the yarns were measured on an Elima tensile tester which works on the base of constant rate of elongation (CRE). A gauge length of $25 \mathrm{~cm}$, clamp speed of $20 \mathrm{~cm} /$ min were used and 20 samples were tested in each case.

To determine the coefficient of friction of yarns, four glass rods with a diameter of $17 \mathrm{~mm}$ assembled on the yarn tensile tester (as shown in Figure 1). Yarn samples were threaded as shown in Fig. 1 to the moving clamp (A) and a $5 \mathrm{~g}$ weigh of $\mathrm{D}$. The pulling force with a contact angle of $720^{\circ}$ at the clamp speed of $25 \mathrm{~cm} / \mathrm{min}$ was measured.

Table 2: Analysis of variance (ANOVA) of yarn properties

\begin{tabular}{llccccc}
\hline & & $\begin{array}{c}\text { Sum of } \\
\text { Squares }\end{array}$ & df & $\begin{array}{c}\text { Mean } \\
\text { Square }\end{array}$ & F & Sig. \\
& Between Groups & 36.914 & 6 & 6.152 & 2.139 & 0.05 \\
Tenacity(cN/tex) & Within Groups & 382.603 & 133 & 2.877 & & \\
& Total & 419.518 & 139 & & & 0.00 \\
Strain at peak & Between Groups & 971.577 & 6 & 161.929 & 42.649 & \\
& Within Groups & 504.979 & 133 & 3.797 & & 0.00 \\
& Total & 1476.556 & 139 & & & \\
& Between Groups & 2.742 & 6 & .457 & 4.024 & \\
& Within Groups & 15.106 & 133 & .114 & & \\
& Total & 17.848 & 139 & & & \\
& Between Groups & .001 & 6 & .000 & 3.436 & \\
& Within Groups & .002 & 63 & .000 & & \\
\hline
\end{tabular}


Displacement of fibre towards the root was used as a measure of descaling. If a wool fibre is rubbed along its length in a reciprocal mode, quality and form of its scales will determine its displacement toward the root. The lower the displacement, the higher is the damage to the scales. This principle was used for evaluation of descaling. For this purpose, the fibres were rubbed reciprocally along their length for an amplitude of $20 \mathrm{~mm}$ between two glass plates of $A$ and $B$. The button glass $(A)$ was covered with a

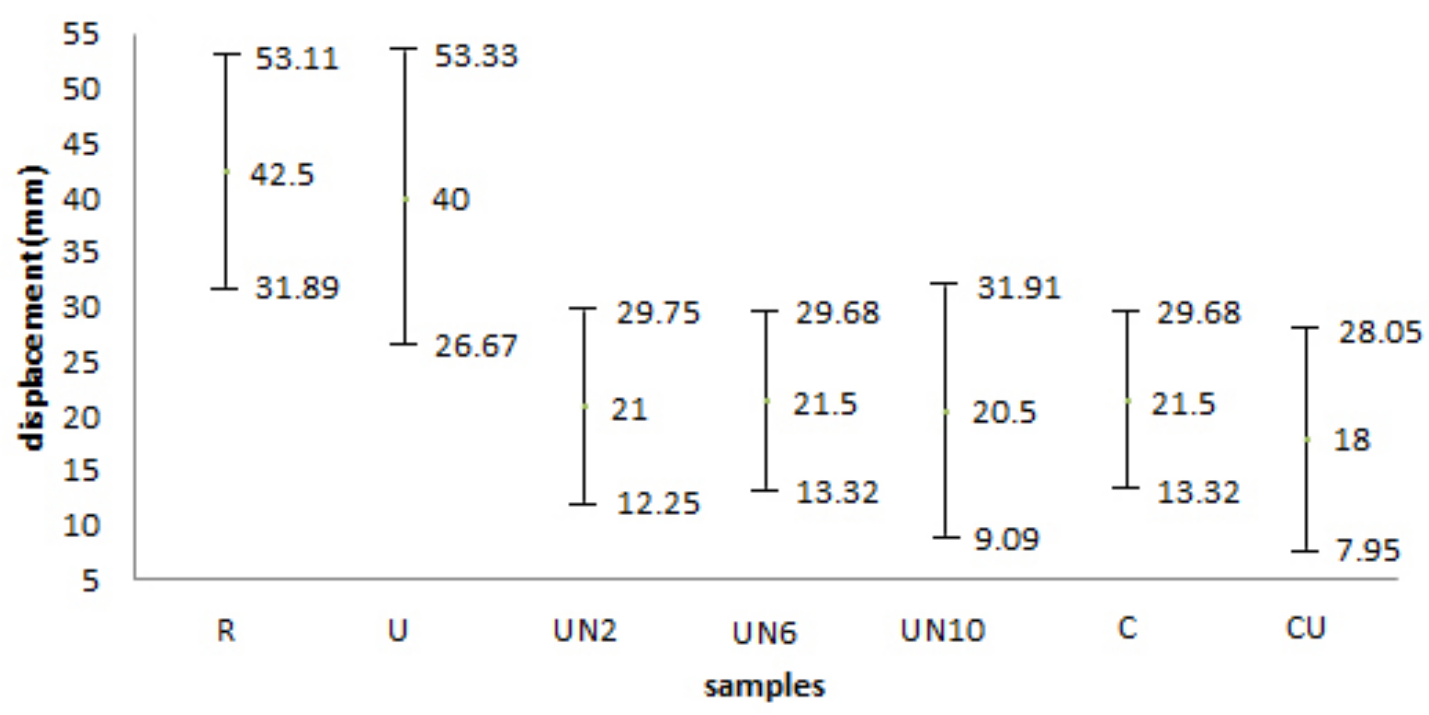

Fig. 4: Mean directional displacement of fibres

Table 3: Tukey test of ranking for results of yarn properties

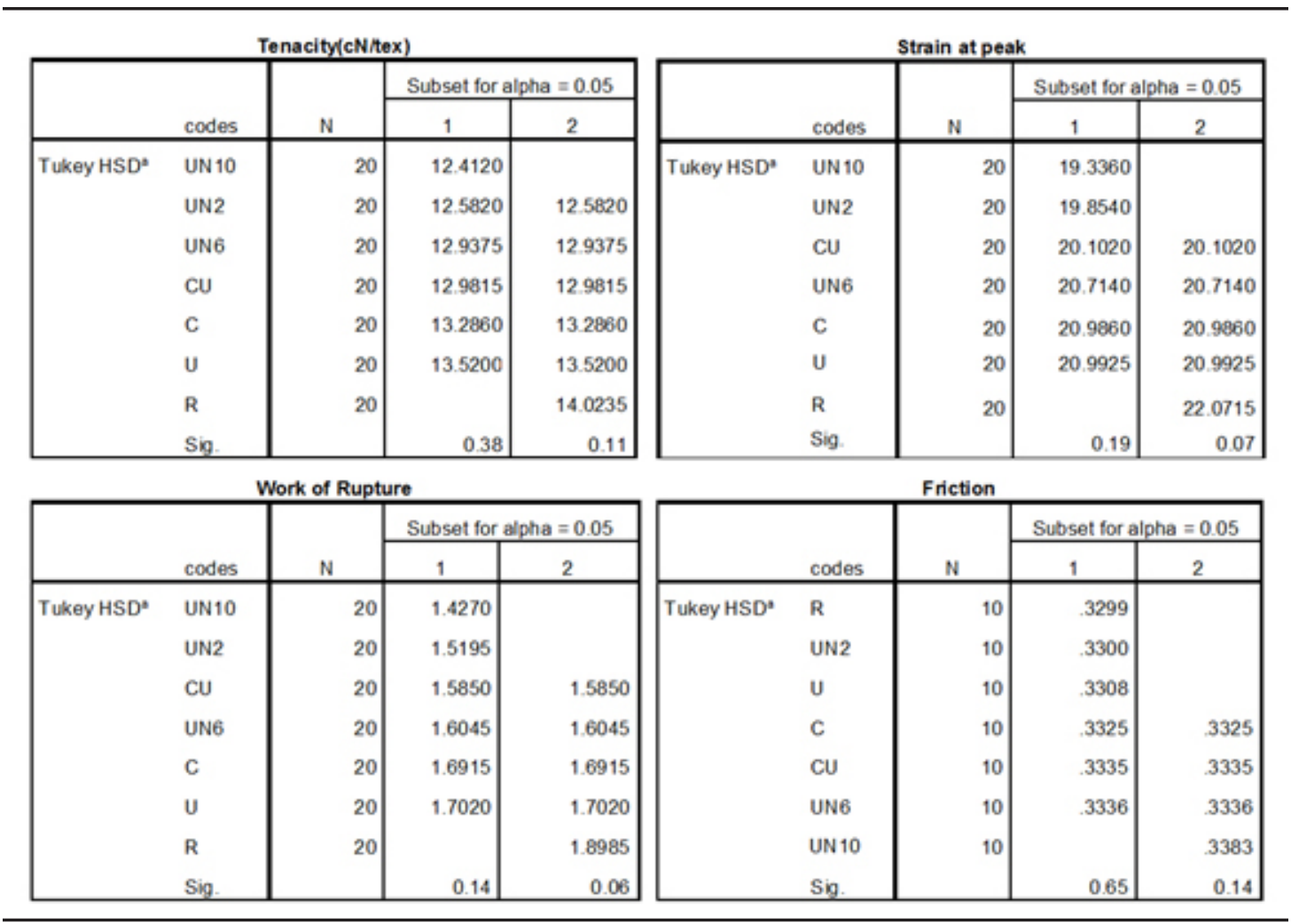


$\mathrm{mm}$-scaled paper and the upper glass (B) was first covered with a sponge layer of $1.5 \mathrm{~mm}$ thickness and then with a layer of $80 \mathrm{~g} / \mathrm{m}^{2}$ paper. Each fibre was rubbed for 10 cycles and the displacement was recorded. Ten fibres were tested in each case. The test parameters were selected by trial and error and according to the results of a M.Sc. dissertation ${ }^{26}$. Figure 2 shows schematic diagram of the plates and the fibre. For studying surface of the fibres, LEO Scanning Electron Microscope model 440i (SEM)

Table 4: Analysis of variance (ANOVA) of directional displacement of fibres

\begin{tabular}{lccccc}
\hline & Sum of Squares & Df & Mean Square & F & Sig. \\
\hline Between Groups & 6267.143 & 6 & 1044.524 & 9.986 & 0.00 \\
Within Groups & 6590.000 & 63 & 104.603 & & \\
Total & 12857.143 & 69 & & & \\
& & & & & \\
\hline
\end{tabular}

Table 5: Tukey test of ranking for directional displacement of fibres

\begin{tabular}{ccccc}
\hline \multicolumn{4}{c}{ Subset for alpha = 0.05 } \\
& Code & N & $\mathbf{1}$ & $\mathbf{2}$ \\
\hline Tukey HSD & & & \\
& CU & 10 & 18.00 & \\
UN10 & 10 & 20.50 & \\
UN2 & 10 & 21.00 & \\
UN6 & 10 & 21.50 & \\
C & 10 & 21.50 & \\
U & 10 & & 40.00 \\
R & 10 & & 42.50 \\
Sig. & & 0.98 & 0.99 \\
\hline
\end{tabular}

was used. The fibres were coated with gold prior to SEM imaging.

\section{RESULTS AND DISCUSSION}

Test results of yarn tenacity, strain at peak, work of rupture and coefficient of friction are given in figure 3. Analysis of variance of yarn properties (ANOVA) for comparison of means and Tukey test for ranking of yarn properties are given in tables 2 and 3.

According to ANOVA test for yarn properties in table 2, sig. values of $0.05,0.00,0.00$ and 0.00 , indicate that there are a significant statistical

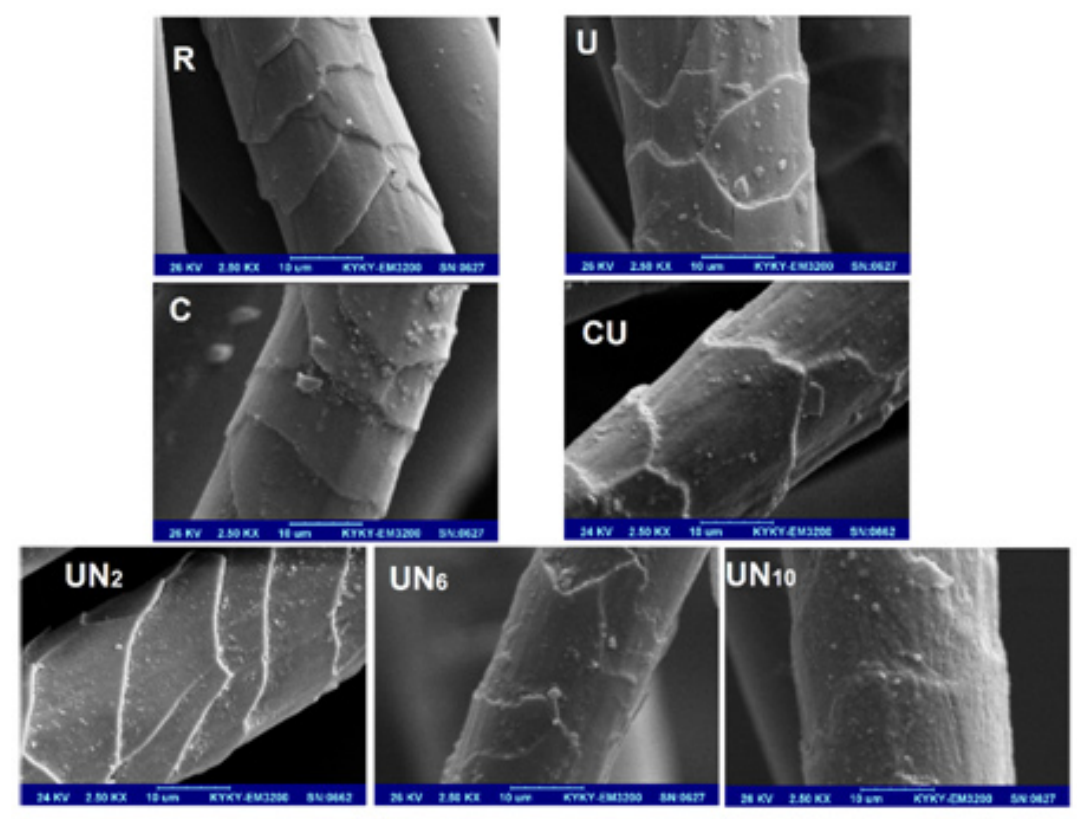

Fig. 5: SEM images of samples 
difference between the means of yarn properties. Strength of yarns UN10 and R were minimum (12.4 cN/tex) and maximum (14.0 cN/tex) respectively. There was no significant difference between tenacity of rest of the yarns with UN10 and R yarns. Concentration of the Nano abrasive in the rage of 2 to $10 \mathrm{~g} /$ lit didn't affect yarn tenacity.

Results of yarn strain in table 3 shows that, strain of UN10 and UN2 yarns were significantly lower than that of $\mathrm{R}$ yarn. There was no difference between strains of the above yarns with rest of the yarns. Therefore, concentration of nano- $\mathrm{CaCO}_{3}$ didn't have significant effect on strain of the yarns. Also, sonication affected yarn strain in comparison to the raw wool, but it didn't has any effect on chlorinated yarn. Behavior of work of rupture of the yarns were the same as their strain. Tukey test of ranking for yarn coefficient of friction (YCF) in table 3 shows that, YCF of $U N 10$ is significantly greater than that of $R, U$ and UN2 yarns. There is no difference between YCF of the above mentioned yarns with rest of the yarns. Therefore, sonication didn't have any effect on YCF of the raw wool and the increase in concentration of Nano abrasive material from 2 to $10 \mathrm{~g} /$ lit increased YCF significantly.

Directional frictional effect (DFE) of the fibres was evaluated with directional displacement of the fibres (DDF) due to a reciprocal rubbing action between two glass plates as described in 2.2. Results of DDF are given in figure 4. ANOVA of DDF results and their Tukey test of ranking are given in tables 4 and 5. Significance value of the ANOVA of DDF in table 4 is 0.00 and indicates that there is a difference between the means. Tukey test of ranking shows that, DDF of $R$ and $U$ fibres are significantly greater than that of rest of the fibres. It may be concluded that, chlorination and Nano treatment of the fibres affect their DFE to the same extent and concentration of the Nano particle in the range of 2 to $10 \mathrm{~g} /$ /it doesn't have any effect on DFE of the fibres.

To investigate effect of Nano abrasive on surface of the fiber, scanning electron microscope
(SEM) images of surface of the fibres were studied. Figure 5 shows SEM images of the fibres. A comparison of raw and sonicated wool in $\mathrm{R}$ and $\mathrm{U}$ samples doesn't show a clear difference in terms of scale removal. But, effect of the increase in concentration of CCNP from 2 to $10 \mathrm{~g} /$ lit is obvious and may be observed in UN2, UN6 and UN10 samples. Sharpness of edge of the scales start to worn in UN2 fibre, it intensifies in UN6 and finally becomes nearly flat in UN10 fibre. This indicates that, sonicated Nano abrasive treatment modifies surface of the fibre effectively and it intensifies with the increase in concentration of the CCNP. Edge of the scales are worn and lost their sharpness in chlorinated and ultrasound assisted chlorinated samples $\mathrm{C}$ and $\mathrm{CU}$. It is difficult to recognize effect of sonication on chlorinated wool when there is a reasonable wear of the scales.

Scales lost their sharpness in descaling and it reduced directional coefficient of friction of the fibre. As a result directional displacement of the fibre reduced, which causes wool felting.

\section{CONCLUSIONS}

It may be concluded from the test results that, Nano abrasive treatment removed a thin layer from surface of the fibres and changed sharpness of the scales. Tenacity, strain and work of rupture of the Nano abraded sample (UN10) reduced and its coefficient of friction increased in comparison to the raw wool, which is not avoidable in other methods of descaling as well. Directional displacement of the fibre, as a measure of directional friction and felting intensity, decreased for Nano treated and chlorinated samples. SEM images showed that, scales could be modified (UN6) or nearly removed (UN10) with this method. Since the Nano abraded material is recyclable and this method of descaling doesn't have any pollutant for our environment, it may be used as a novel, green and environmental friendly method of wool descaling instead of other commercial and environmentally pollutant methods. 


\section{REFERENCES}

1. Zahn, H.; Wool, Aachen, Federal Republic of Germany. 2005, 1

2. Van Der Vegt, A.K.; A Study on the Mechanism of Wool Felting, Uitgeverij Excelsior. 1996, 957-963

3. Morton, W.E., Hearle, J.W.S.; Physical Properties of Textile Fibers. Textile Institute. $1993,635$.

4. Frishman, D., Smith, A. and Harris, M.; Measurement of the Frictional Properties of Wool Fibers. Textile Research Journal.1948, 475-480.

5. Martin, A.J.P. In 'Van Der Vegt, A.K.; A Study on the Mechanism of Wool Felting, Uitgeverij Excelsior. 1996, 957-963'.

6. Rudall, K.M. in 'Van Der Vegt, A.K.; A Study on the Mechanism of Wool Felting, Uitgeverij Excelsior. 1996, 957-963'.

7. Bowman, F.H., in 'Van Der Vegt, A.K.; A Study on the Mechanism of Wool Felting, Uitgeverij Excelsior. 1996, 957-963'.

8. Ditzel, W., In '] Van Der Vegt, A.K.; A Study on the Mechanism of Wool Felting, Uitgeverij Excelsior. 1996, 957-963'.

9. Martin, A.J.P. (1944), In '] Van Der Vegt, A.K.; A Study on the Mechanism of Wool Felting, Uitgeverij Excelsior. 1996, 957-963'.

10. Bradbury, J.H.; Separation and analysis of scale-Rich Material from Wool. Nature. 1959, 183, 305-306.

11. Haly, A.R.; the Propagation of Excitation Energy in Keratin. Trans. Far. Soc. 1960, 56, 1252-1259.

12. Snaith, J.W.; A Method of Removing the Outer Layers of Animal Fibers. Textile Research Journal. 1960, 30, 543.

13. Bradbury, J.H. and Chapman, G.V.; The Chemical Composition of Wool, part1: The Separation and Microscopic characterization of Components Produced by Ultrasonic Disintegration, Aust. J. Biol. Sci. 1964, 17, 960- 972.

14. Bradbury, J.H. and Chapman, G.V. and King, N.L.R.; The Chemical Composition of Wool, part3: Analysis of Cuticle, Skin Flakes and Cell Membrane Material, Proc. Third Intern. Wool Textile Res. Conf., Paris. 1965, 359366.
15. Bradbury, J.H., chapman, G.V. and King N.L.R.; Separation of Chemically Unmodified Histological Components of Keratin Fibers and Analysis of Cuticles, Nature. 1966, 210, 1333-1334.

16. Bradbury, J.H. and Peters, D.E.; Method for the Complete Removal of Cuticle from Wool Fibers, Textile Research Journal. 1972, 42:4, 248-250.

17. Speakman, J.B. and Whewell, E.; the Use of Abrasives to Make Wool Unshrinkable, Journal of the Textile Institute Transaction. 1945, 36:3, 48-56.

18. King, in 'Speakman, J.B. and Whewell, E.; the Use of Abrasives to Make Wool Unshrinkable, Journal of the Textile Institute Transaction. 1945, 36:3, 48-56.'

19. Schumacher, K. and Heine E.; Extremozymes for Improving Wool Properties. J. Biotechnology. 2001, 89, 281-288.

20. Goudarzi, G., Sepehrizadeh, Z., Tabatabaei Yazdi, M. and Jamshidiha, M.; Comparison of Surface Modification of Wool Fibres Using Pronase, Trypsin, Papain and pepsin. Fibres \& Textiles in Eastern Europe. 2008, 90-92

21. Khajavi, R. and Azari, P.; Effect of Ultrasound Irradiation on Wet Wool Chlorination Treatment. Pakistan Journal of Biological Sciences.2007, 10, 2732-2735.

22. Li, Q., Lin, T., Wang,X.; Effects of Ultrasonic Treatment on Wool Fibre and Fabric Properties. J. Text. Inst. 2012, 103 (6), 662-668.

23. Li, Q., Hurren, C.J., Yu, H., Ding, C., Wang, $X$. Thermal and Mechanical Properties of Ultrasonically Treated Wool. Text. Res. J. 2012. 82 (2), 195-202.

24. Daga K, Loonker S, Gupta V, Singh A. V, Rajendra. Physico-Chemical Investigation on Carpet Grade Wool and its Effluent. Orient $J$ Chem 2001; 17(3).

25. Maleknia L, Fard G. C, Ekhlasi F. Study effect corona discharge on morphology, wettability and antibacterial of leather. Orient $J$ Chem 2015;31(Special Issue1).

26. Ghavidel H.; M.Sc. Dissertation, Science and Research Branch Islamic Azad University, Tehran, Iran.2009. 